\title{
Study on the impact abrasive wear of new super-high manganese steel
}

\author{
Wenyan Wang, Henan University of Science and Technology
}

\begin{abstract}
Based on the traditional Mn13, the super-high manganese steel Mn18 was melted by means of adjusting the amount of $\mathrm{C}$ and $\mathrm{Mn}$, adding a certain amount of alloying elements $\mathrm{Cr}$ and $\mathrm{Mo}$ etc and modification. The results show that with low-impact energy abrasive wear for $60 \mathrm{~min}$, the wear resistance of super-high manganese steel Mn18 was greatly improved, in contrast with that of $\mathrm{Mn} 13$, and the hardness of wear surface was increased slowly with the elapse of the wear time. Under the high impact energy, the wear resistance of Mn18 was 1.5 times as high as that of Mn13, and the hardness of wear surface increased to HB440 in a short time. The main wear forms were cutting, gouging wear, and plastic deformation. Typical TEM morphologies of subsurface wear structure consist mostly of high density dislocations and deformation bands.
\end{abstract}

KEYWORDS: super-high manganese steel, wear-resistance, microstructure 